\title{
Odontogenic tumor, cholangioarcinoma and gastric fibroma in a dog - case report
}

\author{
Arlinda Coleto ${ }^{1 *}$, Ana Letícia Silva ${ }^{1}$, Ligia Gundim ${ }^{1}$, \\ Patricia Tivelli ${ }^{1}$, Alessandra Medeiros ${ }^{2}$
}

\begin{abstract}
RESUMO
Os tumores odontogênicos produtores de amiloide são neoplasias raras. Os colangiocarcinomas e fibromas também são referidos como infrequentes. Objetivou-se relatar o caso de um cão, 17 anos, poodle, que foi atendido no Hospital Veterinário da Universidade Federal de Uberlândia. À necropsia, o animal apresentou único nódulo localizado na cavidade oral, da mesma forma, único nódulo no parênquima hepático e ademais, múltiplas massas no estômago. Microscopicamente, as características histológicas foram compatíveis com tumor odontogênico produtor de amiloide, colangiocarcinoma e fibroma, respectivamente. Relatos de ocorrência simultânea de tumores distintos são escassos na literatura.

Palavras-chave: Neoplasia, Boca, Fígado, Estômago, Canis lupus familiaris.
\end{abstract}

\section{Introdução}

Os tumores odontogênicos são derivados do epitélio odontogênico e possuem prognóstico mais favorável em comparação a outras neoplasias da cavidade oral. No tipo produtor de amiloide, há deposição de matriz amiloide tanto no estroma fibroso quanto na porção epitelial (DUBIELZIG, 2002; MUNDAY et al., 2017).

O colangiocarcinoma é uma neoplasia hepática primária maligna, incomum em todas as espécies animais. Geralmente, origina-se do epitélio dos ductos biliares intra-hepáticos, assim como podem ter origem extra-

\footnotetext{
1 Programa de Residência Uniprofissional em Medicina Veterinária da Universidade Federal de Uberlândia.

2 Professora Doutora de Patologia Animal, Universidade Federal de Uberlândia.

* Corresponding author: arlindacoleto@hotmail.com

Endereço: Rua Niquelina, 15, Dona Zulmira, Uberlândia-MG

Telefone: 34991979502
} 
hepática ou vesicular e são envoltos por um estroma fibroso responsável pela textura firme do tumor (JOHNSON e SHERDING, 2008; RADLINSKY, 2015; CULLEN, 2017). A presença de mucina no interior dos túbulos ou ácinos é frequentemente observada (CULLEN, 2009; CULLEN, 2017).

O fibroma é uma neoplasia benigna, originada a partir da proliferação de células mesenquimais do tecido conjuntivo fibroso. É incomum, porém, quando presente, nos cães observa-se em maior número (HENDRICK, 2017).

Relatos da ocorrência concomitante destes tumores em cães são escassos e, assim sendo, objetivou-se relatar a presença de tumor odontogênico, colangiocarcinoma e fibroma em um cão.

\section{Relato de caso}

Um cão, poodle, de 17 anos, foi atendido no Hospital Veterinário da Universidade Federal de Uberlândia. O animal apresentava hiporexia, hipodipsia e incapacidade funcional dos membros pélvicos associada à hipotrofia muscular, além de cegueira bilateral e surdez. Diante do prognóstico desfavorável, o proprietário e o clínico optaram pela eutanásia sem a realização de exames complementares. O animal foi encaminhado para o setor de Patologia Animal.

$\mathrm{Na}$ necropsia, observou-se opacidade bilateral de córnea, doença periodontal severa na cavidade oral e nódulo localizado na região superior lateral direita entre o palato duro e o palato mole, com 2,0 cm de diâmetro, firme, brancacento, de superfície irregular (Figura 1A). O fígado apresentava bordas moderadamente abauladas e fluindo moderada quantidade de sangue ao corte. Presença de nódulo firme com $0,5 \mathrm{~cm}$ de diâmetro, brancacento e de aspecto umbilicado, com extravasamento da cápsula (Figura 2A). O estômago apresentava na serosa da curvatura maior, três massas de $4 \times 3 \times 2 \mathrm{~cm}, 3 \times 2 \times 1 \mathrm{~cm}$ e $2 \times 2 \times 2 \mathrm{~cm}$, firmes, brancacentas, com 
focos milimétricos amarelados em seu interior que rangiam ao corte (Figura 3A). Na avaliação do sistema locomotor, não foram observadas alterações macroscópicas que justificassem a paralisia dos membros posteriores, somente atrofia bilateral dos músculos pélvicos.

Diversos fragmentos foram coletados das lesões, acondicionados em formol tamponado a $10 \%$ e encaminhados ao Laboratório de Histopatologia para posterior confecção de lâminas histológicas.

$\mathrm{Na}$ avaliação microscópica do tumor oral, foi identificada proliferação neoplásica de células epiteliais com crescimento expansivo e bem delimitado; as células apresentaram-se dispostas em cordões e ilhas; de entremeio observou-se material amorfo eosinofílico (Figura 1B); morfologicamente caracterizaram-se por formato poligonal, com citoplasma abundante eosinofílico, núcleo arredondado periférico com cromatina frouxa e nucléolo único ou múltiplo proeminente; pleomorfismo celular baixo. Através da coloração Vermelho Congo, foi possível destacar a matriz amiloide (Figura 1C). A partir destes achados diagnosticou-se tumor odontogênico produtor de amiloide. 
Figura 1. Tumor odontogênico produtor de amiloide. Cão, 17 anos, poodle. A) Massa localizada na transição palato duro - palato mole, no osso maxilar (seta). B) Proliferação neoplásica de células epiteliais com crescimento expansivo e bem delimitado; as células apresentam-se dispostas em cordões e ilhas. HE, objetiva de 4x. C) Nota-se a matriz amiloide (seta). Vermelho congo, objetiva de 40x.

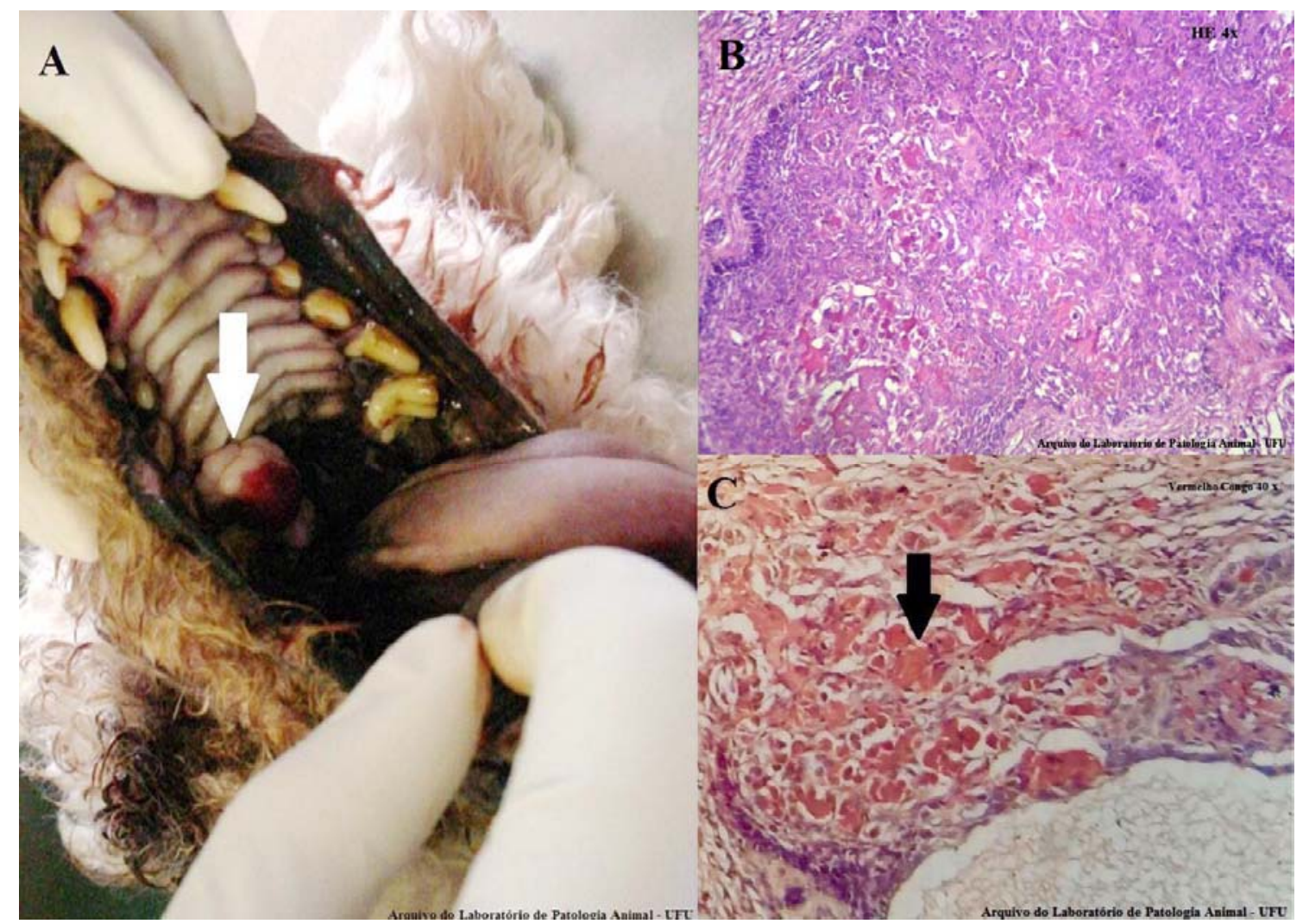

Fonte: o autor.

No fígado, observou-se proliferação epitelial com crescimento invasivo e mal delimitado, formando túbulos (Figura 2B); as células possuíam formato poligonal e citoplasma vacuolizado, núcleo central arredondado, cromatina frouxa e nucléolos únicos ou múltiplos proeminentes (Figura 2C); pleomorfismo celular moderado; discreta quantidade de material amorfo eosinofílico no interior dos túbulos. Diagnóstico: histológico de colangiocarcinoma. 
Figura 2. Colangiocarcinoma. Cão, 17 anos, poodle. A) Nódulo em lobo hepático (setas). B) Proliferação neoplásica de células epiteliais com crescimento invasivo e mal delimitado (setas maiores); apresentaram-se dispostas em túbulos (setas menores). HE, objetiva de $4 \mathrm{x}$. C) Detalhe das células tumorais (setas) e formação de túbulo (asterisco). HE, objetiva de $40 \mathrm{x}$.
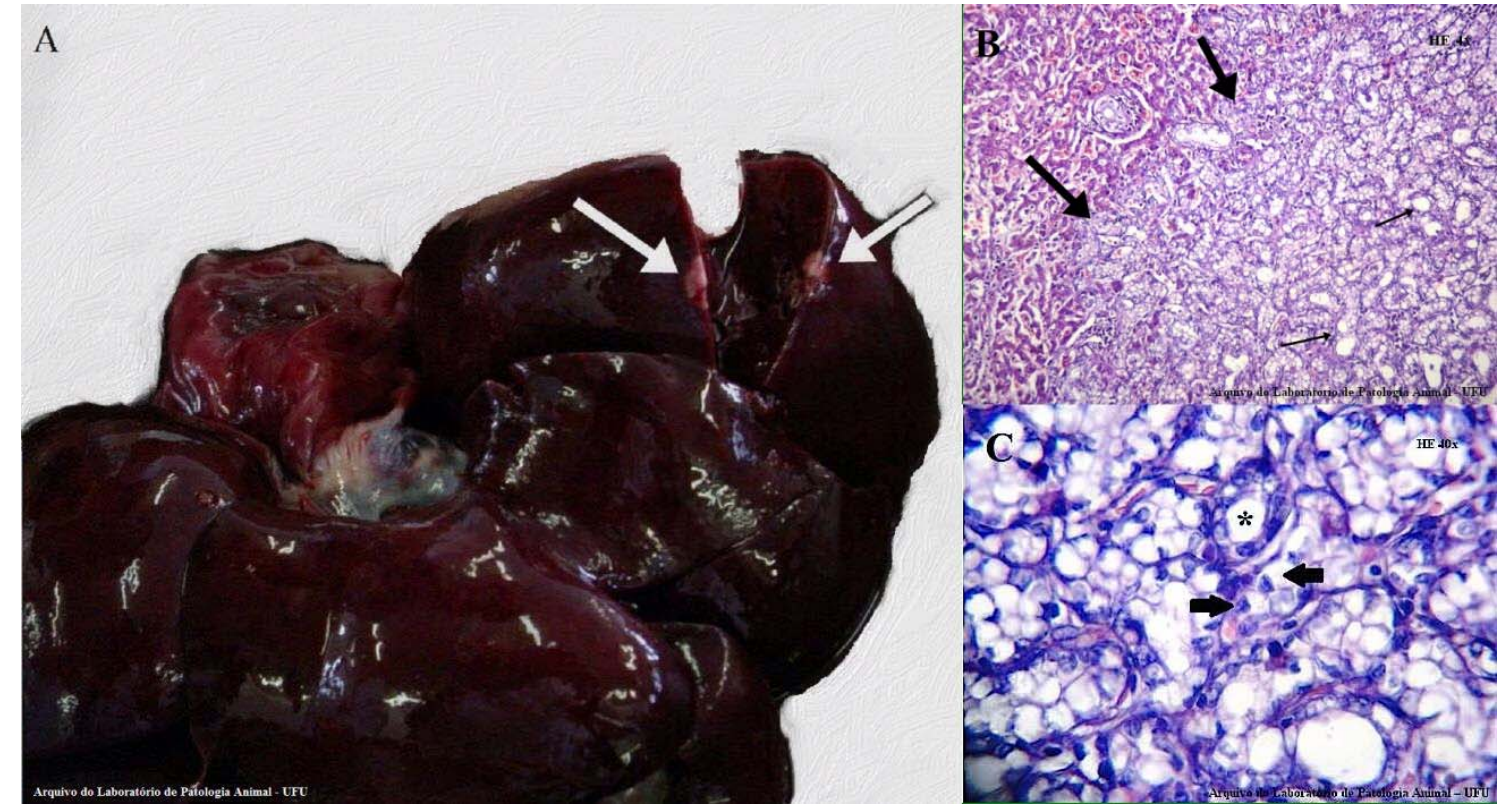

Fonte: o autor.

$\mathrm{Na}$ amostra de tecido gástrico, foi observada proliferação de células fusiformes dispostas em fascículos (Figura $3 \mathrm{~B}$ ); citoplasma eosinofílico, núcleo central alongado, cromatina frouxa e nucléolos únicos ou múltiplos proeminentes; baixo pleomorfismo celular, sendo atribuído diagnóstico de fibroma. Foram observadas, ainda, áreas de necrose com calcificação. 
Figura 3. Fibroma. Cão, 17 anos, poodle. A) Massas localizadas na serosa do estômago (setas). B) Proliferação neoplásica de células mesenquimais dispostas em fascículos. HE, objetiva de 40x.

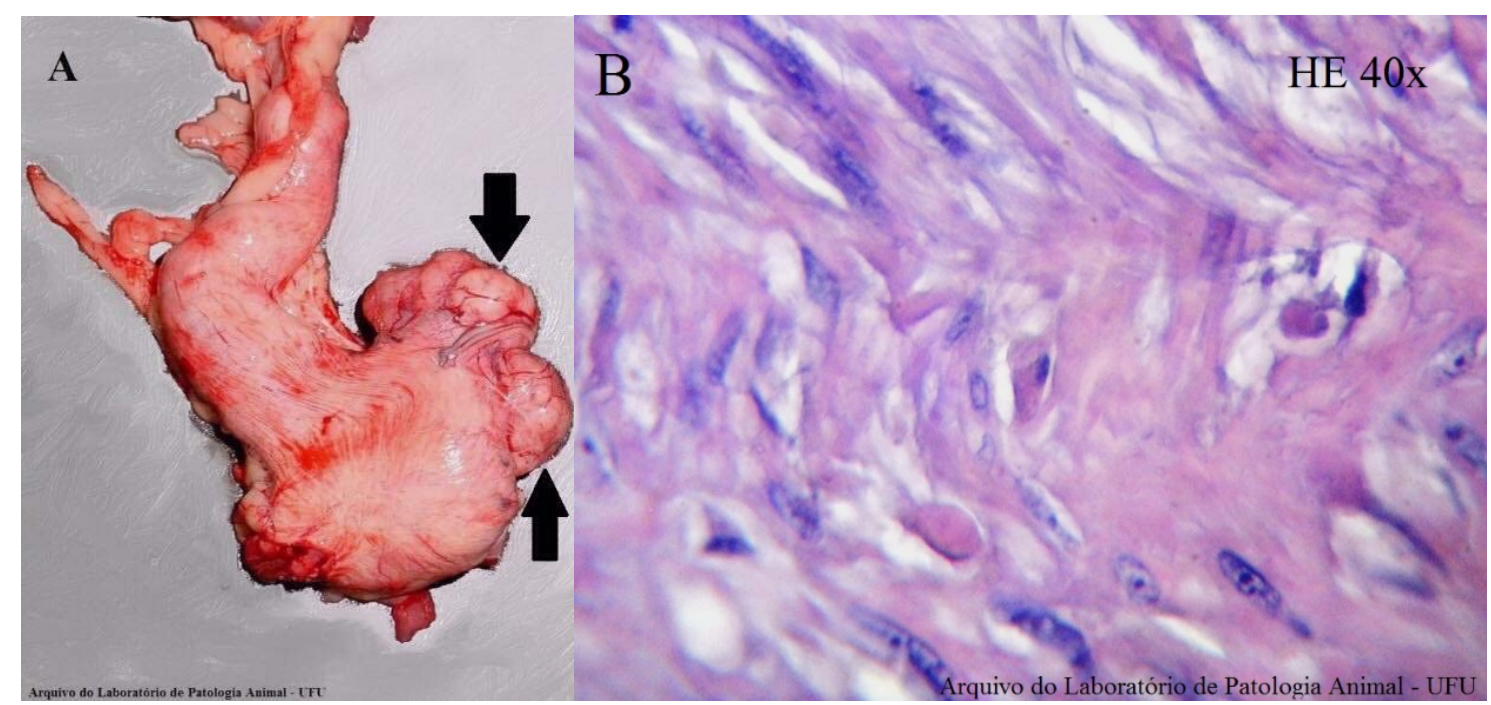

Fonte: o autor.

\section{Discussão}

Os tumores odontogênicos produtores de amiloide são raros, representando de 1,0 a 4,0\% das neoplasias de origem odontogênica em cães. A localização abrange a maxila ou a mandíbula, o que corrobora com o presente caso. Os achados histológicos da lesão oral foram semelhantes às descritas por Dubielzig (2002) e Munday et al. (2017), em que as células epiteliais estão distribuídas em ilhas ou cordões e envolvidas em abundante estroma fibroso. Há deposição de quantidades variáveis de amiloide por todo o parênquima tumoral.

O colangiocarcinoma manifesta-se em 65\% dos caninos com idade superior a 10 anos (CULLEN e POPP, 2002; CULLEN, 2017), dado que corrobora com o presente relato, visto que o animal tinha 17 anos. Os achados macroscópicos e histopatológicos se assemelham aos descritos por Johnson (2000), Cullen (2009) e Cullen (2017), os quais observaram massa 
solitária ou lesões multifocais nodulares que variavam de 0,5 a $4,0 \mathrm{~cm}$ de diâmetro, firmes, branco-acinzentadas, com áreas de necrose central e aspecto umbilicado quando há rompimento da cápsula. Histologicamente, há presença de células epiteliais cuboidais a colunares com núcleos redondos a ovalados e nucléolos proeminentes, dispostas em túbulos ou ácinos. A presença de mucina no lúmen tubular ou acinar é frequentemente observada, eosinofílica a fracamente basofílica pela coloração de hematoxilina e eosina. As células tumorais estão envoltas por tecido conjuntivo, responsável pela textura firme caraterística. Apesar de o colangiocarcinoma ser uma neoplasia maligna e que frequentemente produz metástases, não se observou, durante exame macroscópico, massas tumorais em outros tecidos.

Fibromas são caracterizados pela proliferação benigna de fibrócitos que produzem colágeno. Possuem consistência firme ou elástica, são bem circunscritos, mas não encapsulados. A conformação é ovoide, em forma de cúpula ou polipoide, com diâmetro que varia de 1,0 a 5,0 cm e superfície de corte branco-acinzentada (SCOTT et al., 2001; HENDRICK, 2017), aspectos semelhantes aos observados neste caso. A histopatologia do nódulo gástrico evidenciou características semelhantes às descritas por Hendrick (2017) e Gross et al. (2005), sendo composto por fibrócitos maduros que produzem colágeno. As fibras colágenas são normalmente organizadas em fascículos entrelaçados e configuração ligeiramente ondulante. Os fibrócitos neoplásicos são bem diferenciados, uniformes, com núcleos ovais monocromáticos e nucléolo evidente. O citoplasma é indistinto, que converge com o estroma extracelular.

Na literatura, há escassez de relatos sobre a ocorrência simultânea de neoplasias, visto ainda a particularidade de serem incomuns nos caninos. $\mathrm{O}$ animal em questão era portador destas neoplasias independentes entre si. 


\title{
Odontogenic tumor, cholangioarcinoma and gastric fibroma in a dog - case report
}

\begin{abstract}
Odontogenic tumors producing amyloid are rare neoplasms. Cholangiocarcinomas and fibromas are also referred to as infrequent. The objective of this study was to report the case of a dog, 17 years old, a poodle, who was treated at the Veterinary Hospital of the Federal University of Uberlândia. At necropsy, the animal presented only nodule located in the oral cavity, in the same way, only nodule in the hepatic parenchyma and in addition, multiple masses in the stomach. Microscopically, the histological features were compatible with odontogenic tumor producing amyloid, cholangiocarcinoma and fibroma, respectively. Reports of simultaneous occurrence of distinct tumors are scarce in the literature.

Keywords: Neoplasm, Mouth, Liver, Stomach, Canis lupus familiaris.
\end{abstract}

\section{Referências}

CULLEN, J. M. Fígado, sistema biliar e pâncreas exócrino. In: McGAVIN, M. D.; ZACHARY, J. F. Bases da Patologia em Veterinária. 4 ed. São Paulo: Elsevier, 2009.

CULLEN, J. M. Tumors of the liver and gall bladder. In: MEUTEN, D. J. Tumors in Domestic Animals. 5. ed. Ames, Iowa: John Wiley \& Sons Inc., 2017.

CULLEN, J. M.; POPP, J. A. Tumors of the liver and gall bladder. In: MEUTEN, D. J. Tumors in Domestic Animals. 4. ed. Iowa: Iowa State Press, 2002. https://doi.org/10.1002/9780470376928.ch9

DUBIELZIG, R. R. Tumors of the Alimentary Tract. In: MEUTEN, D. J. Tumors in Domestic Animals. 4. ed. Iowa: Iowa State Press, 2002.

MUNDAY, J. S.; LÖHR, C. V.; KIUPEL, M. Tumors of the Alimentary Tract. In: MEUTEN, D. J. Tumors in Domestic Animals. 5. ed. Ames, Iowa: John Wiley \& Sons Inc., 2017.

GROSS, T. L.; IHRKE, P. J.; WALDER, E. J.; AFFOLTER, V. K. Skin Diseases of the Dog and Cat: Clinical and Histopathologic diagnosis. 2. ed. Oxford: 
Blackwell Science Ltd, Blackwell Publishing, 2005. https://doi.org/10.1002/9780470752487

HENDRICK, M. J. Tumors of the skin and soft tissues. In: MEUTEN, D. J. Tumors in Domestic Animals. 5. ed. Ames, Iowa: John Wiley \& Sons Inc., 2017.

JOHNSON, S. E. Chronic hepatic disorders. In: ETTINGER, S, J.; FELDMAN, E. C. Textbook of veterinary internal medicine diseases of the dog and cat. 5 . ed. Philadelphia: W. B. Saunders, 2000.

JOHNSON, S. E.; SHERDING, R. G. Doenças do fígado e trato biliar. In: BIRCHARDS, S. J.; SHERDING, R. G. Manual Saunders: Clínica de Pequenos Animais. 3. ed. São Paulo: Roca, 2008.

RADLINSKY, M. G. Cirurgia do fígado. In: FOSSUM, T. W. Cirurgia de Pequenos Animais. 4. ed. Elsevier Brasil, 2015.

SCOTT, D. W.; MILLER, W. H.; GRIFFIN, C. E. Neoplastic and non-neoplastic tumors. In: SCOTT, D. W.; MILLER, W. H.; GRIFFIN, C. E. Muller \& Kirk's Small Animal Dermatology. 6. ed. Philadelphia: Saunders, 2001. https://doi.org/10.1016/B978-0-7216-7618-0.50024-9 